\title{
OS TRÊS NÍVEIS DO CONHECIMENTO QUÍMICO: dificuldades dos alunos na transição entre o macro, o submicro e o representacional
}

\author{
Mayara Soares de Melo' \\ Roberto Ribeiro da Silva²
}

\begin{abstract}
RESUMO
Estudos apontam que uma das maneiras de se ensinar Química na educação básica é por meio da discussão dos três níveis do conhecimento químico. Porém, no contexto das aulas de Ciências há uma falta de demarcação desses níveis quando os fenômenos são apresentados, gerando dificuldades no aprendizado dos conceitos. A partir desses fatos, surge a necessidade de se investigar como fazer a transição entre os três níveis de modo a auxiliar a compreensão dos conceitos apresentados nas aulas de Química. Para tanto, foram investigadas duas hipóteses, a saber: a utilização de sistemas conceituais hierárquicos e o uso de modelos e modelagem, associados à realização de atividades demonstrativo-investigativas. A utilização dessa estratégia levou a resultados bastante satisfatórios, pois, com o uso de sistemas conceituais, os estudantes se apropriaram dos significados dos conceitos abordados e, por meio das atividades de modelos e modelagens, conseguiram representar os fenômenos observados utilizando diferentes modos de representação.
\end{abstract}

Palavras-chave: Três níveis do conhecimento químico. Modelos e modelagens. Sistemas conceituais.

\section{THE THREE LEVELS OF CHEMICAL KNOWLEDGE: students' difficulties in the} transition between macro, submicro and representational

\begin{abstract}
Studies point out that one of the ways to teach Chemistry in basic education is through discussion of the three levels of chemical knowledge. However, in the context of Science classes there is a lack of demarcation of these levels when phenomena are presented, generating difficulties in the learning of chemical

\footnotetext{
1 Mestra em Ensino de Ciências pela Universidade de Brasília (UnB). Professora da área de Ensino de Química na Universidade Federal do Oeste da Bahia (UFOB), Barreiras/BA/Brasil e Doutoranda em Educação em Ciências pela UnB/Brasília/DF/Brasil. Orcid iD: https://orcid.org/0000-0002-1494-9183. E-mail: mayara.sdemelo@gmail.com

2 Doutor em Química. Professor Voluntário Sênior na UnB - Instituto de Química - Brasília - DF -
} Brasil. Orcid iD: https://orcid.org/0000-0003-0805-5594. E-mail: bobsilva@unb.br
\end{abstract}


concepts. From these facts emerges the need to investigate how to make the transition between the three levels. In order to do that, two hypotheses were investigated: the use of hierarchical conceptual systems and the use of models and modeling, associated with demonstrative-investigative activities. The use of this strategy led to quite satisfactory results, because with the use of conceptual systems students appropriated the meanings of the concepts addressed and, through the activities of models and modeling they managed to represent the phenomena observed, using different modes of representation.

Keywords: Three levels of chemical knowledge. Models and modeling. Conceptual systems.

\section{LOS TRES NIVELES DEL CONOCIMIENTO QUÍMICO: dificultades de los alumnos en la transición entre lo macro, lo submicro y lo representacional}

\section{RESUMEN}

Los estudios muestran que una de las maneras de enseñar Química en la educación básica es a través de la discusión de los tres niveles del conocimiento químico. Sin embargo, en el ámbito de las clases de Ciencias, hay una falta de demarcación de esos niveles frente a los fenómenos presentados generando, de esta manera, dificultades en el aprendizaje de los conceptos. A partir de estos hechos surge la necesidad de investigar cómo hacer la transición entre los tres niveles de modo a auxiliar la comprensión de los conceptos presentados en las clases de Química. Para esto, han sido investigados dos hipótesis, a saber: la utilización de sistemas conceptuales jerárquicos y el uso de modelos y modelado, asociados a la realización de actividades demostrativo-investigativas. La utilización de esta estrategia llevó a resultados bastante satisfactorios, pues, con el uso de sistemas conceptuales, los estudiantes se apropiaron de los significados de los conceptos abordados y, por medio de las actividades de modelos y modelajes, lograron representar los fenómenos observados utilizando diferentes modos de representación.

Palabras clave: Tres niveles del conocimiento químico. Modelos y modelado. Sistemas conceptuales.

\section{INTRODUÇÃO}

A forma como a Química é ensinada na educação básica tem sido objeto de estudo de inúmeras pesquisas na educação em Ciências. Esses trabalhos apontam os motivos pelos quais jovens não se interessam em estudá-la e, em muitos casos, apresentam níveis insatisfatórios de compreensão dos conceitos discutidos nessa área de conhecimento.

Dentre os motivos que explicam esse desinteresse e o baixo rendimento dos estudantes, podemos destacar: a forma estanque como os 
conteúdos são apresentados, não sendo entendidos como elaboração humana e passíveis de mudanças; a falta de discussões sobre como os conceitos se relacionam com o contexto, fazendo com que os alunos acabem memorizando-os, sem compreendê-los; os currículos são inadequados, favorecendo um ensino fragmentado e distante da realidade.

Na busca por um ensino de Química que traga explicações para os fenômenos e possibilite uma melhor relação com as teorias, podem ser utilizadas ferramentas como a experimentação, mais, especificamente, as atividades demonstrativo-investigativas. Essas atividades são desenvolvidas utilizando como aporte teórico os estudos de Johnstone (2009), que defende a necessidade de se discutir o conhecimento químico em seus três níveis: o macro e tangível, o molecular e invisível, e o simbólico e matemático. Silva, Machado e Tunes (2019), ao apresentarem as atividades demonstrativoinvestigativas, sugerem que na condução dessas atividades sejam explicitados esses três níveis, chamados por eles de macroscópico, interpretação submicroscópica e expressão representacional.

Apesar de a abordagem dos três níveis do conhecimento químico ser amplamente difundida no ensino de Química, existem muitas lacunas sobre como promover estratégias que auxiliem os estudantes na transição entre cada um deles. Pensando nisso, em uma das atividades propostas nas aulas de Química para uma turma do $1^{\circ}$ ano do Ensino Médio, após mostrar uma equação química que representava determinado fenômeno, foi solicitado que os estudantes fizessem outra representação, utilizando desenhos de esferas representando as substâncias envolvidas na reação. Analisando a resposta dessa e de outras atividades realizadas, percebemos que muitos estudantes sentem dificuldade em transitar entre um modelo de natureza atômico-molecular e as equações químicas relacionadas a esses modelos.

Em virtude desse problema surge a seguinte questão: Por que os alunos não transitam entre os três níveis do conhecimento químico?

$\mathrm{Na}$ busca por soluções para esse problema, investigamos duas principais hipóteses: a primeira diz respeito ao fato de que a forma como os conceitos são apresentados aos alunos não permite que eles estabeleçam 
relações lógicas entre esses conceitos, isto é, não permite o desenvolvimento do pensamento conceitual.

A segunda diz respeito à forma como é feito o uso de modelos e modelagem, não sendo explicitado como os modelos são construídos, para quais finalidades e suas limitações.

Assim, o objetivo dessa pesquisa foi investigar de que forma pode-se favorecer a transição entre os níveis: macroscópico, submicroscópico e representacional, de modo a contribuir para o processo ensinoaprendizagem em Química.

\section{O QUE SÃO OS TRÊS NÍVEIS DO CONHECIMENTO QUÍMICO?}

A ideia dos três níveis do conhecimento químico foi proposta ainda na década de 1980 por Johnstone (1982). Nesse trabalho, ele apresenta um modelo para explicar os diferentes níveis de representação do conhecimento químico, argumentando que a falta de abordagens que transitem entre cada um deles contribui para muitas das dificuldades observadas no processo ensino-aprendizagem de Química.

Johnstone (2010) relata que muitos dos problemas observados naquela época ainda estão presentes na atualidade. Nesse trabalho, os três níveis foram renomeados e apresentados em um triângulo exibido na Figura 1.

Figura 1 - Três níveis do conhecimento químico

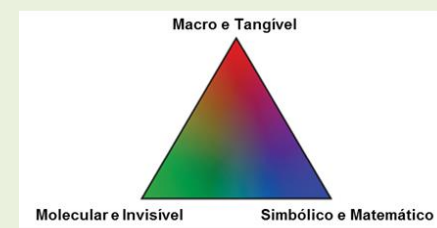

Fonte: Johnstone (2010, p. 24, tradução nossa)

Segundo Johnstone (2010), ao ensinar Química, os professores desenvolvem abordagens situadas em diferentes partes do triângulo. Por exemplo: em uma aula sobre transformações químicas, o professor faz um experimento colocando um comprimido efervescente em um copo com água e pede que os estudantes observem. Neste caso, tem-se uma 
abordagem voltada para o nível macro e tangível, estando situada no vértice do triângulo. Quando o professor discute o fenômeno apresentado utilizando conceitos e modelos de natureza atômico-molecular, ele utiliza uma abordagem situada em um ponto da aresta entre o vértice macro e tangível e o vértice molecular e invisível. Essa abordagem poderá estar situada mais próxima do nível molecular e invisível, caso a ênfase neste nível seja maior do que no macro e tangível, ou vice-versa.

Porém, um dos grandes problemas apresentados por Johnstone (2010) é que os professores discutem a Química, a partir do centro do triângulo, tratando simultaneamente dos três níveis sem que haja uma distinção de cada um deles por parte dos estudantes.

Nesses casos, a falta de compreensão dos conhecimentos está relacionada a sobrecargas nas memórias de trabalho dos estudantes. Elas ocorrem porque o pensamento consciente possui um espaço de trabalho limitado para desempenhar duas funções: armazenar e processar informações temporárias. Quando são recebidas muitas informações, sobra pouco espaço para processá-las e o aprendizado fica comprometido. Uma forma de minimizar esse problema é iniciar a abordagem a partir do macro e tangível, que é familiar aos estudantes e, gradualmente, enriquecê-la com os níveis molecular e invisível e simbólico e matemático (JOHNSTONE, 2010).

Na literatura, é a ampla a variedade de nomenclaturas dadas aos três níveis do conhecimento químico. Gilbert e Treagust (2009) apresentaram pelo menos dez nomes distintos, tais como: nível macroscópico, macro, macro e tangível; nível microscópico, micro, submicro; e simbólico ou representacional. Essa variedade demonstra uma falta de consenso entre os pesquisadores sobre quais terminologias são mais adequadas para se referirem a cada aspecto. Além disso, esses autores entendem que os termos micro ou microscópico podem levar a possíveis ambiguidades, fazendo com que os estudantes pensem que é possível realizar observações desse nível com o auxílio de equipamentos, tais como, um microscópio. Como forma de evitar esse equívoco, é sugerida a utilização do prefixo "sub" junto ao nível microscópico. 
Portanto os estudantes, ao observarem as propriedades e transformações em aulas de Ciências em nível macroscópico, as interpretam a partir de explicações carregadas de suas vivências. Quando o professor discute o nível submicroscópico são introduzidos conceitos ainda mais abstraídos da realidade que fazem uso de uma linguagem específica dessa área de conhecimento. E, ao apresentar as expressões representacionais, as explicações são reescritas utilizando símbolos e fórmulas. Cabe ao professor, por meio da linguagem, possibilitar que os significados dos estudantes se ampliem, favorecendo na apropriação de novos conceitos.

Deste modo, para melhor entender como se dá a apropriação dos conceitos científicos pelos estudantes e o papel do professor e da escola nesse processo, discutiremos as ideias de Vigotski (2007) sobre os conceitos cotidianos e conceitos científicos e sua relação com o ensino de Ciências.

\section{O PENSAMENTO POR CONCEITOS COTIDIANOS E POR CONCEITOS CIENTÍFICOS}

Para Vigotski (2007), o pensamento e a fala, no início da vida da criança, têm linhas de desenvolvimento distintas. Durante seu crescimento, a partir do convívio com o outro, ela aprende o nome das coisas ao seu redor. Nessa fase em que a criança sente a necessidade da palavra, inaugura-se o chamado pensamento verbal, momento em que as funções: fala e pensamento se unem, formando uma unidade dialética, tornando-se verbal o pensamento e intelectual a fala.

Para Vigotski (2007), é no significado da palavra que se encontra a mais simples unidade do pensamento verbal. E um dos aspectos fundamentais de sua teoria é o entendimento de que esses significados se desenvolvem ao longo da vida, na interação social e nos diferentes contextos. Ele distingue pelo menos duas classes do pensamento verbal, devido às diferentes condições nas quais os significados se desenvolvem, que são: os conceitos cotidianos e os conceitos científicos. Fuhr (2018) traz a diferença entre esses conceitos:

os cotidianos são constituídos na experiência diária e estão estruturados de forma assistemática, possibilitando o enraizamento da pessoa na vida do dia a dia, enquanto que os científicos 
estruturam-se em sistemas hierárquicos de coordenação e subordinação lógicas, desenvolvidos na instrução formal escola, possibilitando o desenvolvimento da consciência reflexiva, o pensar sobre o próprio pensar (p.42).

Para exemplificar a utilização de conceitos cotidianos podemos pensar na seguinte situação: um professor pergunta aos estudantes o que é um metal, tendo como objetivo ouvir as concepções deles sobre o assunto abordado. Em seguida, os alunos respondem: ferro, cobre, ouro. Nesse contexto, a palavra metal é uma categoria abstraída que se refere a um conjunto de objetos. Vigotski (2007) denomina esse tipo de significado, que relaciona a palavra diretamente ao objeto, de conceito cotidiano.

O pensamento por conceitos científicos envolve o desenvolvimento de processos psicológicos complexos que, para Vigotski, ocorrem, especialmente, na escola. Esse modo de pensar, diferentemente do cotidiano, tem conceitos mediados por outros conceitos, e caracteriza-se por ser organizado em um sistema hierárquico de inter-relações.

O aprendizado desses conceitos exige que os estudantes desenvolvam uma consciência reflexiva, se apropriando de regras lógicas que permitam ligar um significado a outro, refletindo sobre seu próprio ato de pensar.

Desse modo, a partir dos estudos de Vigotski (2007), percebe-se a importância de, ao se ensinar os conceitos químicos, perceber as interrelações e hierarquias entre eles. Para Tolentino e colaboradores (1986):

[...] um sistema de conceitos científicos deve se caracterizar por apresentar uma hierarquização de conceitos, segundo sua abrangência, orientando-se dos mais abrangentes para conceitos subjacentes, menos abrangentes, com relações de subordinação bem definidas (p. 1722).

Tolentino et al. (1986) analisaram sistemas conceituais presentes em livros didáticos e perceberam diversos equívocos como a falta de uma hierarquia e a presença de diferentes conceitos em um mesmo nível, apesar de não serem excludentes entre si. Pensando nessas falhas, além da análise, Silva et al. (1986) e Tunes et al. (1989) propuseram novos sistemas, 
considerando a natureza da matéria, suas formas de apresentação, a natureza de seus constituintes, e a natureza dos átomos de seus constituintes, considerando a lógica do pensamento científico proposta por Vigotski.

No primeiro trabalho, eles apresentam um sistema conceitual para natureza da matéria ilustrado na Figura $2 a$. Para cada um dos conceitos que participam do sistema, foi proposto um enunciado: matéria: "tudo aquilo que, no universo, ocupa lugar no espaço" (TOLENTINO et al., 1986, p. 1723); material: porção de matéria formada por mais de uma substância.

Ao analisar a organização do sistema conceitual apresentado, percebe-se uma relação lógica entre os conceitos, na qual o conceito de substância é subordinado ao de material, e o de material ao de matéria.

Figura 2 - Sistemas conceituais: a) formas de apresentação da matéria b) natureza da matéria

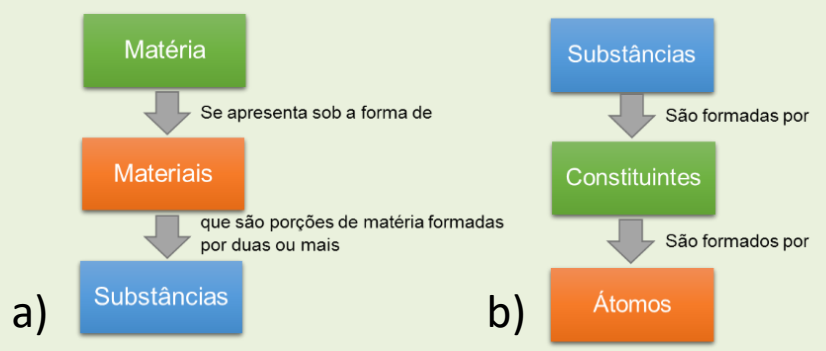

Fonte: a) Adaptado de Tolentino et al. (1986) b) Adaptado de Rocha-Filho et al. (1988).

Em relação ao conceito de substância, Rocha-Filho et al. (1988) a definiram como sendo uma porção de matéria que possui apenas um tipo de constituinte. A partir desse conceito, é apresentado outro sistema hierárquico que se refere à natureza da matéria (Fig. 2b). Além de substância, eles definiram constituintes como sendo a "unidade que dá identidade a uma substância" (Rocha-Filho et al., 1988, p. 417).

Nesse sistema conceitual, ressalta-se a importância do conceito de constituinte, pois é essencial que a substância não seja entendida como um conjunto de átomos que possui propriedades resultantes da soma das características de cada um deles, mas sim, como sendo formada por unidades que seriam "a entidade que identifica inequivocamente a 
substância a que define, do ponto de vista epistemológico, como a unidade analítica da Química" (Rocha-Filho et al., 1988, p. 417).

Os sistemas conceituais apresentados, conforme proposto por Vigotski, buscam organizar os conceitos de acordo com relações lógicas de subordinação e coordenação. Faz-se necessário que os alunos compreendam cada um dos níveis hierárquicos para evitar que eles apenas memorizem os conceitos apresentados tendo foco somente no objeto. Deste modo, as aulas favorecerão o desenvolvimento de estruturas superiores de generalização por parte dos estudantes.

Ao pensar em estratégias que possam favorecer a transição entre os níveis apresentados nos sistemas propostos, acreditamos que a utilização de modelos e modelagem pode contribuir para uma melhor compreensão do conhecimento químico. No ensino fundamentado na modelagem, o professor deverá possibilitar que os estudantes tenham experiências com o fenômeno para construção e testes dos modelos elaborados, favorecendo o contato com o nível macroscópico.

\section{A UTILIZAÇÃO DE MODELOS E MODELAGEM NO ENSINO DE QUÍMICA}

Justi (2011) define modelos como sendo representações parciais de uma entidade, criadas tendo em vista um ou mais objetivos específicos que podem ser modificados. Porém, muitos professores apresentam concepções equivocadas desse conceito, entendendo os modelos como cópias ou reproduções da realidade. Equívocos como esses acabam contribuindo para visões simplistas apropriadas pelos estudantes como, por exemplo, no estudo dos modelos atômicos, em que alguns acreditam que os modelos apresentados são ampliações dos átomos ou que o modelo mais atual está pronto e acabado.

Com isso, defende-se que nas aulas de Ciências haja uma maior compreensão do que são modelos, como são construídos e quais suas finalidades e limitações. A partir dessas discussões, possibilita-se um conhecimento mais amplo sobre a natureza da ciência, sobre como o conhecimento científico é elaborado e modificado. 
A utilização de modelos no ensino de Química é recomendada para diferentes funções, das quais destacam-se: facilitar no entendimento de fenômenos complexos a partir de representações simplificadas; favorecer abstração de entidades impossiveis de serem visualizadas; servir para fornecer uma base para previsão de funções mais complexas; "fundamentar a proposição e a interpretação de experimentos" e "ser um mediador entre a realidade modelada e teorias sobre ela" (JUSTI, 2011, p. 212).

Em se tratando da discussão da ideia de modelos no ensino de Ciências, uma das dificuldades se deve à complexidade do processo de produção dos modelos (GILBERT, 2004). Eles são fruto de representações pessoais criadas individualmente ou em grupo, inacessíveis aos demais, chamadas de modelos mentais, que passam a serem nomeados modelos expressos, ao serem expostos para outras pessoas. No caso de um grupo social concordar com um modelo expresso, tem-se um modelo consensual. Se for um grupo de cientistas que se utiliza do modelo consensual para o desenvolvimento do conhecimento científico, ele é denominado modelo científico. E quando um modelo científico aceito em outro contexto é substituído, ele passa a ser chamado modelo histórico.

Apesar de sua importância, são poucos os trabalhos que discutem sobre como as habilidades de modelagem podem ser desenvolvidas. Pensando nessa questão, Justi e Gilbert (2002) desenvolveram um esquema em que são apresentadas e discutidas as diferentes etapas envolvidas na construção de modelos. Eles entendem que, apesar da dinamicidade e criatividade nesse processo, existem etapas inerentes às atividades de modelagem, que são explicadas a seguir:

A Etapa 1 se refere à produção de um modelo mental e é composta por três subetapas que são: a definição dos objetivos, ter experiências e uma origem para o modelo. Para realização dessa atividade é fundamental que se tenha conhecimento ou que se definam os objetivos para os quais tal modelo será elaborado. Os modelos elaborados em sala de aula nem sempre irão corresponder ao modelo curricular e o professor não deve ficar preso a ele como sendo o único modelo "correto", pois os estudantes 
podem produzir modelos diferentes que sejam coerentes e com poder de previsão adequado tal como os curriculares (MENDONÇA, 2011).

Na Ełapa 2 deve-se escolher qual será a forma de representação nessa atividade. Para isso, o professor pode: deixar que os estudantes escolham a forma de representação; escolher uma forma de representação para que os estudantes a utilizem; ou mostrar diferentes formas de representação e propor que eles escolham a que melhor favoreça na comunicação de suas ideias (JUSTI, 2006).

A Ełapa 3 é a comprovação dos modelos. Nesse momento, os modelos consensuais elaborados são testados por meio de experimentos mentais ou empíricos. A decisão de utilizar apenas um ou ambos e a ordem em que serão realizados, vai depender dos recursos disponíveis e dos conhecimentos prévios dos estudantes. Caso o modelo falhe, apresentando contradições, ele pode ser modificado e testado novamente.

Diante do exposto, nesta pesquisa foi investigada a utilização de estratégias que envolvam a discussão dos três níveis conhecimento químico, por meio da utilização dos sistemas conceituais. A partir das reflexões apresentadas, o trabalho foi desenvolvido utilizando modelos para auxiliar os estudantes na transição entre os níveis submicroscópico e representacional. Com isso, buscou-se contribuir para que eles compreendessem aspectos relacionados à natureza da Ciência, desenvolvessem habilidades de representar os constituintes das substâncias e também entendessem os conceitos apresentados.

\section{PROCEDIMENTOS METODOLÓGICOS}

Visando analisar as possíveis contribuições de atividades envolvendo sistemas conceituais, modelos e modelagem na transição entre os três níveis do conhecimento químico, foi realizada uma pesquisa a partir da realização de uma sequência didática para alunos do $1^{\circ}$ ano do ensino médio de uma escola pública do Distrito Federal. Durante as atividades, foram feitas gravações dos áudios dos encontros, fotos dos materiais produzidos e questionários. 
Foi realizada uma investigação qualitativa que, segundo Bogdan e Biklen (1994) tem as seguintes características: o ambiente natural é a fonte de dados, sendo o pesquisador o principal agente na coleta deles; tem natureza descritiva; interesse maior no processo do que no resultado em si, e busca conhecer os significados apropriados pelos participantes durante 0 processo.

A sequência foi realizada em três encontros, com duração de 1 h e 40 min cada, cujas atividades desenvolvidas foram descritas no Quadro 1. O tema escolhido foi a atmosfera terrestre, cuja discussão envolve moléculas mais simples, facilitando o trabalho com modelos.

Quadro 1 - Atividades realizadas na sequência didática atmosfera terrestre

\begin{tabular}{|c|c|}
\hline Encontro & Atividades desenvolvidas \\
\hline $\begin{array}{c}\text { Encontro } \\
1\end{array}$ & $\begin{array}{l}\text { - Questionário inicial: 1) o que é a atmosfera? 2) o que é o are 3) do que é } \\
\text { constituído o gás nitrogênio, o gás oxigênio e o gás hidrogênio?33 } \\
\text { - Discussão sobre os conceitos de atmosfera e de ar (o que é o ar, quais } \\
\text { substâncias o compõem e os volumes médios de cada um dos gases no ar). } \\
\text { - Apresentação do sistema conceitual, formas de apresentação da matéria } \\
\text { (Fig. 2a) a partir do qual, discutiu-se a classificação do ar como material por ser } \\
\text { composto por mais de uma substância. } \\
\text { - Discussão coletiva, a partir da pergunta: do que os gases presentes no ar são } \\
\text { constituídos? Diálogo sobre a questão, a partir do modelo de Dalton. } \\
\text { - Representação pelos estudantes dos gases nitrogênio, oxigênio e hidrogênio } \\
\text { segundo o modelo de Dalton, usando massa de modelar, e diálogo sobre os } \\
\text { modelos apresentados. } \\
\text { - Contextualização histórica: Discussão sobre as limitações do modelo de } \\
\text { Dalton observadas por Gay-Lussac, a partir de experimentos empíricos. } \\
\text { Levantamento de hipóteses sobre como poderiam modificar o modelo para } \\
\text { resolver o problema apresentado. Apresentação das contribuições de } \\
\text { Avogadro que, introduzindo o conceito de moléculas, solucionou o problema. } \\
\text { - Apresentação do sistema conceitual natureza da matéria (Figura 3). } \\
\text { - Representação pelos estudantes, usando massa de modelar, dos gases } \\
\text { nitrogênio, oxigênio e hidrogênio se baseando nas ideias de Dalton modificadas } \\
\text { por Avogadro (modelo de Dalton modificado). Os constituintes das substâncias } \\
\text { foram representados como moléculas diatômicas. } \\
\text { - O questionário proposto no início da aula foi respondido novamente. }\end{array}$ \\
\hline $\begin{array}{l}\text { contro } \\
2\end{array}$ & $\begin{array}{l}\text { - Revisão das principais ideias trabalhadas na aula anterior. } \\
\text { - Atividade demonstrativo-investigativa: É possível encher uma bexiga sem } \\
\text { assoprá-la? O experimento consistiu em colocar uma bexiga na boca de uma } \\
\text { garrafa e, com um secador de cabelo, soprar ar quente nas paredes da } \\
\text { garrafa. O ar contido na garrafa foi aquecido e a bexiga que antes estava } \\
\text { murcha, encheu-se (observação macroscópica). Após a observação, os } \\
\text { estudantes foram questionados sobre como a Ciência explica o fenômeno. } \\
\text { Solicitou-se que eles pensassem nos sistemas conceituais discutidos na aula }\end{array}$ \\
\hline
\end{tabular}

${ }^{3}$ A análise dos resultados obtidos para as questões 1 e 2 foi publicada em um evento científico.

Revista Exitus, Santarém/PA, Vol. 9, N 5, P. 301 - 330, Edição Especial 2019. 


\begin{tabular}{|l|l|}
\hline anterior (Fig. 2a; Fig. 2b) e estabelecessem relações entre os conceitos \\
abordados. \\
- Representação, por meio de um desenho, do sistema observado antes e após \\
o aquecimento e dos constituintes das substâncias segundo o modelo de Dalton \\
modificado. Os estudantes foram questionados sobre as representações para \\
analisar como eles entenderam o fenômeno. \\
• A partir dos modelos concretos produzidos pelos discentes e das discussões \\
realizadas, foram categorizadas as representações obtidas.
\end{tabular}

\section{RESULTADOS E DISCUSSÃO}

No primeiro encontro, o sistema conceitual natureza da matéria (Fig.

2b) foi introduzido a partir do questionamento sobre a constituição do ar, conforme exemplificado no trecho abaixo:

Pesquisadora: A gente já sabe que o ar é formado por várias substâncias, mas e essas substâncias, cada um desses gases, é formado pelo quê?

Estudante 1: Moléculas.

Estudante 2: Por átomos.

No trecho acima, nota-se que um dos discentes responde que as substâncias presentes no ar são formadas por moléculas, enquanto outro diz que são formadas por átomos. Tais conceitos apresentam níveis de ordenação diferentes no sistema conceitual natureza da matéria, sendo as moléculas um tipo de constituinte e, portanto, um conceito supraordenado ao de átomo.

A diferenciação entre os conceitos de átomo e moléculas foi realizada a partir de uma abordagem histórica em que foram introduzidas, inicialmente, as ideias de Dalton para explicar do que eram constituídas as substâncias presentes no ar. Em seguida, eles construíram modelos buscando 
representar os constituintes de três substâncias presentes no ar: gás oxigênio, gás nitrogênio e gás hidrogênio, segundo o modelo proposto.

A maior parte dos modelos concretos expressos pelos alunos representavam esferas de tamanhos semelhantes simbolizando cada um dos constituintes dos gases. Tais modelos se adequavam às ideias de Dalton.

Também foram observados modelos que divergiam das ideias de Dalton. Nesses casos, foi solicitado que os estudantes explicassem o motivo de terem representado os constituintes daquela forma. Um deles representou os constituintes das substâncias nitrogênio, oxigênio e hidrogênio de tamanhos diferentes. Ao ser questionado sobre o motivo de ter proposto tal representação, o estudante respondeu que o fez devido aos diferentes volumes das substâncias presentes no ar limpo e seco. Por exemplo, como o teor de gás nitrogênio no ar é maior, o constituinte dessa substância foi representado como sendo uma esfera maior. Ou seja, esse estudante confundiu o volume dos constituintes das substâncias com o teor dessas substâncias no ar, associando essa medida ao tamanho dos átomos.

Outro estudante representou três conjuntos contendo sete esferas cada, agrupadas com tamanhos semelhantes, para representar os constituintes das substâncias. A explicação do estudante para ter feito tal representação é apresentada no trecho a seguir:

Estudante 3: Cada bolinha é um átomo e cada quantidade de átomo é uma molécula.

A partir dessa explicação observa-se que, mesmo ao abordarmos, inicialmente, apenas as ideias de Dalton sobre os constituintes das substâncias e, portanto, não termos discutido o conceito de molécula, o Estudante 3 traz sua concepção prévia e, em seu modelo, tenta representar as moléculas das substâncias. Percebe-se que, para ele, uma molécula é um aglomerado de átomos.

Buscando evitar o surgimento de concepções equivocadas, como a do Estudante 3 é que defendemos que sejam utilizados sistemas conceituais. Vogelezand (1987) argumenta que problemas como a apropriação do 
conceito de molécula, podem surgir devido a ele ser trabalhado muito precocemente, antes mesmo de ser discutido o conceito de substância.

Esse é, possivelmente, um dos problemas vivenciados pelo estudante em questão. Apesar de a sequência didática ter sido iniciada, abordando o conceito de substância, o conceito de átomo é um dos primeiros a serem abordados no estudo da Química, ainda no final do Ensino Fundamental, o que pode contribuir para concepções equivocadas como essa.

Na segunda etapa realizada foi o teste do modelo. Para isso, visando ilustrar um dos problemas encontrados com o modelo histórico de Dalton, foi escolhida uma reação química envolvendo as substâncias oxigênio e nitrogênio, já representadas pelos estudantes: gás nitrogênio reagindo com o gás oxigênio, formando o monóxido de nitrogênio. Solicitamos que os estudantes representassem essa reação química utilizando o modelo concreto que haviam construído com massinhas de modelar.

Em seguida, a partir de uma contextualização histórica, foi apresentada uma limitação do modelo de Dalton. Foi explicado que, ao realizar a reação de um volume de gás nitrogênio com um volume de gás oxigênio, esperava-se que fosse formado um volume de monóxido de nitrogênio. Porém, a partir de estudos experimentais realizados na época observou-se a formação de dois volumes de monóxido de nitrogênio. Parte da explicação apresentada pode ser observada no trecho a seguir:

Pesquisadora: Era um volume para um volume formando um volume... E o que foi percebido experimentalmente? Gay-Lussac percebeu que, experimentalmente, quando reagia um volume de gás nitrogênio com um volume de gás oxigênio formava dois volumes de monóxido de nitrogênio.

O modelo atômico de Dalton, ao assumir as substâncias oxigênio e nitrogênio como sendo formadas por átomos, não consegue explicar a formação de dois volumes de monóxido de nitrogênio, obtida por GayLussac. Tentando favorecer que os estudantes vislumbrassem possíveis soluções para esse problema, foi solicitado que eles retratassem duas vezes o monóxido de nitrogênio, representando assim, a formação dos dois volumes. Em seguida, pedimos que olhassem para a representação e pensassem em 
como poderiam solucionar tal empasse. O trecho a seguir ilustra o diálogo em que os participantes tentam resolver o problema:

Estudante 4: $O$ experimento dele dev errado.

Pesquisadora: O experimento dele dar errado é uma hipótese. Mas supondo que ele testou esse experimento uma, duas, três vezes, e outras pessoas repetiram esse experimento e aí ao invés de encontrar um volume, ele encontrou dois volumes (...) E agora, como resolver esse problema a partir do que você tem aqui?

Estudante 5: Não tenho nem ideia.

Estudante 6: Tem dois átomos de cada um.

Conforme observado no trecho acima, os estudantes formularam diferentes hipóteses para explicar os motivos que levaram ao problema identificado. A introdução de aspectos históricos permitiu que os estudantes percebessem a construção do conhecimento científico como atividade humana, sujeita a erros e passível de mudanças. Exemplo disso é a resposta do Estudante 4, que traz o erro experimental como uma das possibilidades que geraram o problema em questão.

Já o Estudante 6 apresenta uma possível sugestão que soluciona 0 problema encontrado na época: ele afirma que haveria dois átomos de nitrogênio e dois átomos de oxigênio. A partir dessa resposta foi explicado aos estudantes que essa solução foi proposta por Avogadro, que introduzindo o conceito de molécula trouxe uma modificação para o modelo atômico de Dalton. Assim, os gases oxigênio e nitrogênio, por exemplo, seriam formados por moléculas diatômicas.

Após tal explicação, foi solicitado que os estudantes representassem novamente com as massinhas de modelar a reação entre o oxigênio e 0 nitrogênio formando o monóxido de nitrogênio, utilizando o modelo de Dalton modificado. Após a atividade, os conceitos apresentados foram revisitados, usando o sistema conceitual natureza da matéria (Fig. 2b), entendendo as substâncias estudadas como sendo formadas por constituintes, no caso moléculas, e elas como sendo formadas por átomos.

A apropriação dessas ideias por parte dos estudantes foi analisada a partir dos dados obtidos nos questionários respondidos, antes e ao final do encontro. A pergunta: Do que é constituído o gás nitrogênio, o gás oxigênio e o gás hidrogênio? - teve como objetivo verificar se a partir das atividades 
realizadas, os estudantes passaram a operar com conceitos científicos para respondê-la, utilizando os sistemas conceituais apresentados. Os dados para essa questão foram apresentados na Figura 3 a seguir.

Figura 3 - Classificação das respostas apresentadas pelos estudantes para a pergunta sobre a constituição dos gases

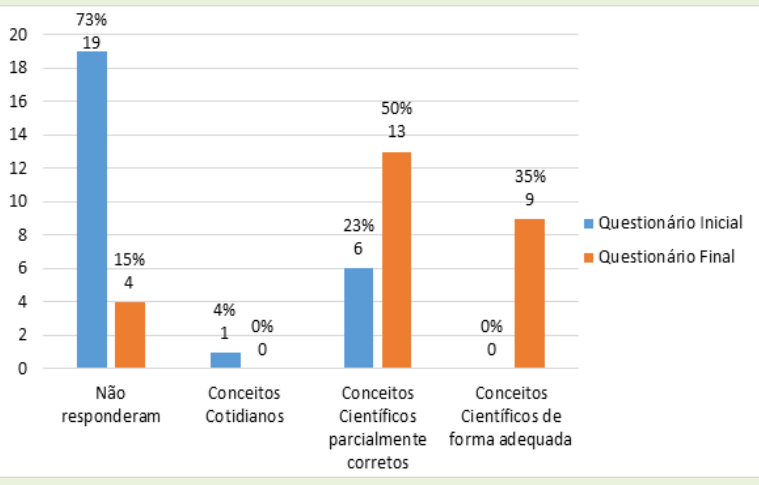

Fonte: do autor

As respostas apresentadas nos questionários inicial e final foram categorizadas em: a) conceitos científicos de forma adequada: quando os estudantes responderam utilizando adequadamente o sistema conceitual; b) conceitos científicos parcialmente corretos: quando observou-se a tentativa de utilizar o sistema conceitual, mas os conceitos foram apresentados de forma inadequada; c) conceitos cotidianos: quando o estudante trouxe suas concepções e essas divergem dos conceitos científicos; e d) não responderam: quando os estudantes não apresentaram resposta.

Observando a Fig. 3 percebe-se que, no questionário inicial, a maior parte dos estudantes (73\% do total) não respondeu à pergunta: do que é constituído o gás nitrogênio, o gás oxigênio e o gás hidrogênio? Além disso, poucos estudantes ( $23 \%$ do total) conseguiram respondê-la usando conceitos científicos, mesmo que parcialmente corretos. Após a realização do primeiro encontro, a maior parte dos alunos respondeu operando com conceitos científicos (50\% parcialmente corretos e 35\% de forma adequada). Percebe-se, portanto, que a discussão do conhecimento químico a partir do uso de sistemas conceituais nas atividades realizadas possibilitou a transição 
entre o nível macroscópico e o submicroscópico, favorecendo que os estudantes passassem a operar o pensamento relacionando conceitos.

No segundo encontro, foram realizadas duas atividades demonstrativo-investigativas. Segundo Melo e Silva (2011), as atividades demonstrativo-investigativas são experiências abertas realizadas no contexto da própria sala de aula.

A primeira delas teve como pergunta inicial: é possível encher um balão sem assoprar? Em seguida, a pesquisadora realizou o experimento e questionou os estudantes sobre possíveis explicações para tal fenômeno. $O$ trecho abaixo ilustra um desses diálogos, em que estudantes tentam propor explicações para o que observaram:

Pesquisadora: Primeira coisa que eu quero perguntar, por que o balão enche?

Estudante 7: Eles se agitam.

Estudante 8: Os átomos ficam tipo mais agitados e o espaço entre eles aumentam.

A partir da pergunta apresentada pela pesquisadora, percebe-se que os Estudantes 7 e 8 tentam operar com conceitos a nível submicroscópico. Há uma tentativa de operá-los a partir dos sistemas conceituais estudados, porém, observa-se que o Estudante 8 ainda entende $\circ$ ar como sendo formado por átomos, não utilizando o conceito de molécula ou constituinte.

Buscando possibilitar que os alunos compreendessem as inter-relações entre os conceitos, ao fazer a interpretação submicroscópica do experimento, foi explicado que quando o ar é aquecido ele expande, e o maior volume é resultante do aumento dos espaços vazios entre as moléculas das substâncias que compõem o ar, usando o sistema conceitual.

Após essa discussão, foi solicitado que os estudantes desenhassem modelos que representassem 0 que ocorre com os constituintes das substâncias antes (estado inicial) e após o experimento (estado final). Ao analisar as representações propostas, foram avaliados os seguintes aspectos:

- Natureza dos constituintes: forma como os estudantes representaram os constituintes das substâncias: se utilizaram o modelo de Dalton modificado, se representaram átomos ou outra forma de representação.

- Distribuição dos constituintes no espaço: foi observado como os constituintes foram distribuídos no espaço, se estavam, uniformemente, separados ou se foram concentrados em partes do recipiente. 
- Conservação do número de constituintes antes e após o experimento: foi verificado se os estudantes consideraram o número de constituintes ao final do experimento como sendo igual ao inicial.

Em relação ao primeiro aspecto, foi observado se os estudantes passaram a representar os constituintes das substâncias como moléculas. As representações foram divididas em categorias: moléculas diatômicas, átomos isolados, moléculas como aglomerado de átomos, outras entidades. Na Tabela 1 são apresentados os dados referentes a esse aspecto.

Tabela 1: Análise dos modelos representados pelos estudantes quanto à natureza dos constituintes

\begin{tabular}{ccccc}
\hline \multirow{2}{*}{ Natureza dos constituintes } & \multicolumn{3}{c}{ Inicial } & Final \\
\cline { 2 - 5 } & $\begin{array}{c}\text { Número de } \\
\text { alunos }\end{array}$ & $\begin{array}{c}\text { Percentual } \\
\text { de alunos }\end{array}$ & $\begin{array}{c}\text { Número de } \\
\text { alunos }\end{array}$ & $\begin{array}{c}\text { Percentual } \\
\text { de alunos }\end{array}$ \\
\hline $\begin{array}{c}\text { Moléculas diatômicas } \\
\text { Átomos isolados }\end{array}$ & 13 & $47 \%$ & 9 & $36 \%$ \\
$\begin{array}{c}\text { Moléculas como } \\
\text { aglomerado de átomos }\end{array}$ & 6 & $21 \%$ & 8 & $32 \%$ \\
(mais de dois átomos) & 6 & $21 \%$ & 5 & $20 \%$ \\
Outras entidades & 3 & $11 \%$ & 3 & $12 \%$ \\
\hline
\end{tabular}

Fonte: do autor

A partir desses dados nota-se que a maioria dos modelos propostos pelos estudantes para ilustrar os constituintes no estado inicial (antes do aquecimento) foram representados utilizando moléculas diatômicas (13 estudantes; $47 \%$ do total). Porém, nos modelos representando a expansão do ar esse número cai (9 alunos; $36 \%$ do total).

A diminuição no número de representações como moléculas diatômicas coincide com o aumento no número de representações do estado final que utilizam átomos isolados. Esse resultado pode ser atribuído à dificuldade no entendimento do fenômeno como resultante do aumento dos espaços vazios entre as moléculas. Para alguns estudantes, o aumento do volume ocorre devido ao aumento dos espaços entre os átomos, com a consequente separação dos átomos das moléculas e representação dos constituintes como átomos isolados. 
A partir desses resultados, percebe-se a importância de discutir conceitos que envolvam a natureza das substâncias partindo de sistemas conceituais. Normalmente, os discentes ao serem introduzidos no estudo da Química, são apresentados aos conceitos fora de uma estrutura lógica definida e acreditam que os átomos são os constituintes das substâncias. A não apropriação do conceito de constituinte pode resultar em dificuldades na compreensão de como ocorrem reações químicas, do significado das equações químicas, das relações estequiométricas etc.

A dificuldade no entendimento do conceito de constituinte também aparece entre seis estudantes (20\% do total) que representaram as moléculas como sendo aglomerados de átomos em seus modelos. Em um desses exemplos, o estudante inicialmente representa os aglomerados de átomos em diferentes grupos, separados de acordo com as substâncias, estando aparentemente estáticos. Após o aquecimento, são utilizadas setas para representar o movimento dos constituintes (Figura 4).

Figura 4: Exemplo de modelo em que as moléculas foram representadas como aglomerado de átomos

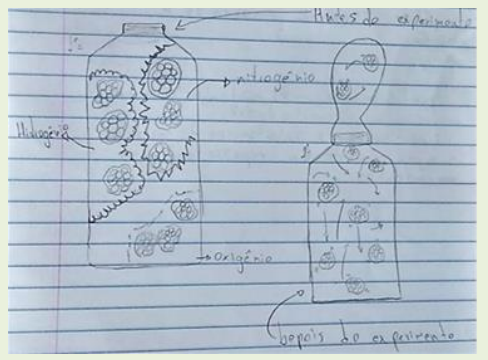

Fonte: do autor

A partir dessa representação, pode-se inferir que o estudante não compreendeu os gases presentes no ar, como sendo formados por moléculas diatômicas, além de entender que as entidades que formam cada uma das substâncias presentes no ar estão estáticas e agrupadas antes do fornecimento de energia ao sistema. Desta forma, é importante que sejam desenvolvidas outras estratégias, que possibilitem aos estudantes entenderem o comportamento dos constituintes das substâncias no estado gasoso. 
Já outros três estudantes (11\% do total) desconsideraram o modelo de Dalton e utilizaram outras representações em seus modelos. Um deles fez um desenho em que as entidades foram representadas usando formas geométricas diferentes. Apesar de a estudante não representar os átomos como esferas, no estado inicial algumas entidades foram apresentadas em pares. A partir dessa representação, percebe-se que a aluna considerou a presença de estruturas formadas por dois átomos no estado inicial, enquanto no estado final, todas as entidades foram apresentadas de forma isolada. A partir dessas informações, verificou-se que, para ela, o aumento da temperatura leva a um aumento dos espaços entre os átomos, fazendo com que eles se separem.

O segundo aspecto avaliado nos modelos foi relativo à forma como os constituintes foram distribuídos no espaço. Na análise das representações, notou-se que alguns alunos, ao desenharem as entidades, as colocaram distribuído-as, uniformemente, em todo recipiente, enquanto outros as concentraram em diferentes partes do recipiente.

Esse aspecto foi também avaliado por Novick e Nussbaum (1978), que analisaram as representações do ar apresentadas por alunos, classificando a natureza das partículas em contínua e particulada, e classificaram as partículas particuladas em: "uniformemente espalhadas, mais espaços entre as partículas; uniformemente espalhadas, partículas expandem para o espaço vazio; concentradas em alguma parte do espaço confinado" (NOVICK; NUSSBAUM, 1978, p. 275, tradução nossa). Baseados nessas categorias, analisamos a forma como as partículas foram distribuídas nos recipientes. Os dados obtidos foram apresentados na Tabela 2.

A partir dos dados observados, nota-se que na maior parte das representações (desenhos de 10 estudantes, $45 \%$ do total), houve um aumento nos espaços vazios entre as entidades, conforme foi discutido durante a atividade demonstrativo-investigativa. Na Fig. 5 são apresentados dois exemplos de representações classificadas nessa categoria. 
Tabela 2: Análise dos modelos representados pelos estudantes quanto à distribuição das entidades

\begin{tabular}{ccc}
\hline Distribuição das entidades & $\begin{array}{c}\text { Número de } \\
\text { modelos }\end{array}$ & $\begin{array}{c}\text { Percentual } \\
\text { de modelos }\end{array}$ \\
\hline Uniformemente espalhados: aumento dos espaços vazios & 10 & $45 \%$ \\
Uniformemente espalhados: diminuição dos espaços vazios & 2 & $9 \%$ \\
Uniformemente espalhados: sem variação aparente nos & 5 & $23 \%$ \\
espaços vazios & 3 & $14 \%$ \\
Concentradas em alguma parte do espaço confinado & 2 & $9 \%$ \\
Outra forma de representação & & \\
\hline
\end{tabular}

Fonte: do autor

Figura 5 - Exemplos de modelos de dois estudantes em que há um aumento dos espaços entre as entidades

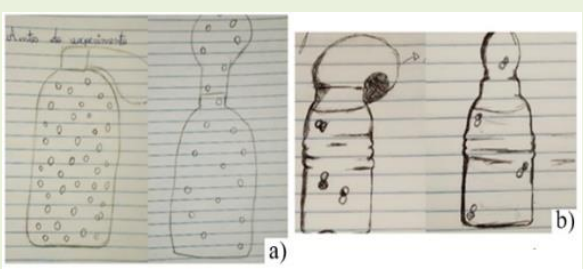

Fonte: do autor

No primeiro desenho (Fig. 5a, à esquerda), a estudante utiliza o modelo de Dalton para representar as partículas e, após o aquecimento do ar, elas ficam mais espaçadas, e no segundo (Fig. 5b, à direita) o estudante representa moléculas, utilizando o modelo de Dalton modificado e também se observa um aumento dos espaços entre as moléculas após o aquecimento. Os resultados são semelhantes aos apresentados por Novick e Nussbaum (1978) que observaram em $46 \%$ das respostas que a natureza dos gases era entendida pelos estudantes como particulada e com as partículas uniformemente separadas por todo espaço.

Já nas representações de outros dois estudantes (9\% do total), foi observada uma diminuição dos espaços vazios entre os constituintes. O exemplo disso é ilustrado na Figura 6 a seguir, na qual a aluna atribui a dilatação do ar ao aumento no tamanho de suas partículas: 
Figura 6 - Exemplo de modelo representado por uma estudante em que foi observada a diminuição dos espaços entre os constituintes

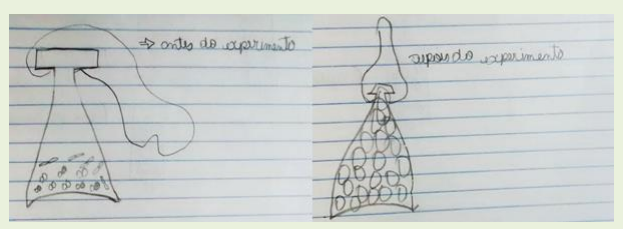

Fonte: do autor.

Esses resultados corroboram os apresentados por Mortimer (1995), ao realizar uma atividade experimental semelhante à desenvolvida nesse encontro, obtendo representações similares à apresentada na Fig. 6:

Esse conceito da dilatação das partículas é muito comum nos modelos atomistas intuitivos elaborados pelos estudantes. Faz parte de uma concepção que chamamos 'atomismo substancialista', uma vez que propriedades macroscópicas das substâncias, como dilatar e mudar de estado, são atribuídas aos átomos e moléculas (Mortimer, 1995, p. 24).

Também foram observados 5 modelos (aproximadamente $23 \%$ do total) em que, apesar dos estudantes representarem as entidades uniformemente separadas, não foi observado aumento nos espaços vazios quando comparadas as representações antes e após o aquecimento do ar. Exemplos disso foram citados anteriormente, em que os alunos inicialmente desenharam representações de moléculas diatômicas, e após o aquecimento representaram átomos separados. Conforme discutido, eles entenderam que com o aumento da temperatura haveria um aumento nos espaços entre os átomos presentes nas moléculas, e não que a expansão do ar ocorre devido ao aumento dos espaços vazios entre as elas.

Voltando à análise da forma como os constituintes foram distribuídos, em 5 representações não foi observada variação aparente nos espaços entre os constituintes antes e após o aquecimento. Exemplo disso é apresentado na Figura 7 a seguir.

Analisando esses modelos, percebemos que a não variação nos espaços vazios normalmente aparece nas representações em que não há uma preocupação com a conservação no número de constituintes antes e 
depois do aquecimento. Na maioria dos modelos (19, mais de $86 \%$ do total) não há preocupação com o número de entidades, sendo representadas em maior número após o aquecimento (Fig. 5b; Fig. 7). Em apenas 3 deles (aproximadamente $14 \%$ do total) a quantidade de entidades é igual antes e depois do processo.

Figura 7 - Exemplo de modelo representado por uma estudante em que não foi observada variação aparente no espaço vazio entre os constituintes

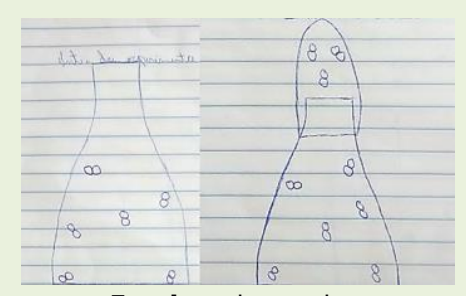

Fonte: do autor

A partir dessa dificuldade, percebe-se que a ideia de conservação da matéria não é bem compreendida por parte dos estudantes mesmo em se tratando do entendimento de transformações físicas, como é o caso da dilatação dos gases.

Outras formas de distribuição foram observadas em 3 modelos em que nas representações as entidades foram concentradas em alguns espaços do recipiente, conforme pode ser observada na Fig. 8 a seguir.

Figura 8 - Exemplo de modelo em que se observa a concentração de moléculas em determinados espaços do recipiente

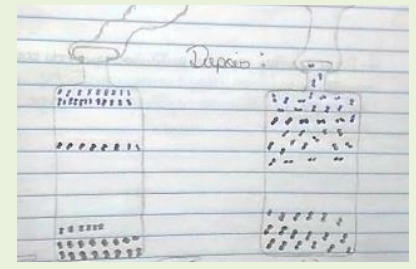

Fonte: do autor

Novick e Nussbaum (1978) relatam ideias semelhantes em seu trabalho, no qual, alguns dos alunos participantes da pesquisa acreditavam que ao 
submeter o ar à ação de uma bomba de vácuo, este ficaria concentrado em partes do recipiente.

A partir desses resultados, percebe-se que mesmo após as discussões realizadas sobre as limitações do modelo de Dalton que levaram a sua modificação, os estudantes ainda apresentaram dificuldades em entender do que são constituídas as substâncias. Apesar disso, quando analisamos os dados apresentados na Figura 3, percebemos que inicialmente, ao serem questionados sobre o que constitui as substâncias, nenhum estudante respondeu utilizando conceitos científicos de forma adequada e após a aula 9 estudantes o fizeram utilizando o conceito de molécula. Avaliando as representações apresentadas após o experimento, observa-se que 9 estudantes representaram os constituintes dos gases como moléculas diatômicas em seus modelos. Portanto, alguns estudantes, além de responderem que os gases são formados por moléculas, passaram a utilizar o conceito de moléculas na representação do fenômeno observado.

O terceiro encontro teve como objetivo discutir a representação dos fenômenos por meio de equações químicas. A atividade foi realizada visando verificar se os estudantes utilizariam os sistemas conceituais para responder a uma questão proposta, entendendo a água como sendo um material por ser formada por várias substâncias, dentre elas o gás oxigênio. Os estudantes tentaram responder à pergunta proposta como pode ser observado na transcrição abaixo:

Pesquisadora: A gente está discutindo o seguinte: como os peixes morreram por falta de oxigênio sendo que eles estavam na água?

Estudante 10: Na água tem moléculas de oxigênio.

Nesse trecho, podemos perceber que o Estudante 10 entende que na água do rio existem, além da substância água, moléculas de oxigênio. Essa percepção é muito importante, pois, nota-se que o aluno sabe diferenciar o átomo presente na substância água do constituinte do gás oxigênio. Conforme explicam Rocha-Filho et al. (1988): "o estudo dos átomos tem sentido para o químico apenas quando concebidos do "ponto de vista do constituinte', isto é, como parte destes" (p. 419), e esse aluno consegue 
perceber essa diferença em se tratando do átomo de oxigênio e do constituinte da substância oxigênio.

Após essa discussão, foi feita a atividade demonstrativo-investigativa: eletrólise da água. Em seguida, foi solicitado que os estudantes representassem, usando massinha de modelar, os constituintes das substâncias envolvidas na eletrólise: água, gás hidrogênio e gás oxigênio, segundo o modelo de Dalton modificado. A maioria representou os gases como moléculas diatômicas e a molécula de água com duas esferas representando o hidrogênio e uma o oxigênio (Figura 9).

Figura 9 - Modelos construídos por estudantes representando os constituintes das substâncias envolvidas na eletrólise da água

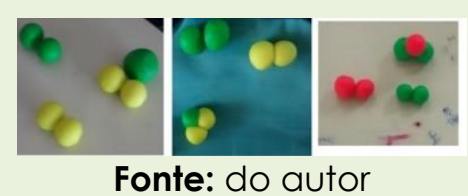

Fonte: do autor

A partir das representações construídas, foi pedido que os estudantes escrevessem a equação química que representa a eletrólise. Observamos que houve dificuldade em realizar tal tarefa, sendo necessário explicar como representamos uma equação química, o que são reagentes e produtos etc. Após a explicação, a partir do modelo, muitos estudantes conseguiram escrever corretamente (totalmente ou parcialmente) a equação química que representa o fenômeno observado.

As expressões representacionais foram classificadas em: totalmente corretas; parcialmente corretas; incorretas e não apresentou. Para essa classificação, foram consideradas totalmente corretas as respostas na qual o estudante apresentou um modelo (representação por meio de um desenho dos constituintes da reação) que se adequava às ideias de Dalton modificadas por Avogadro, e a partir dele, escreveu a equação considerando o número de átomos que formam os constituintes das substâncias e, por isso, fez o devido balanceamento da equação. Um 
exemplo de resposta considerada totalmente correta é apresentado na Figura 10a.

Figura 10 - a) Expressão representacional classificada como totalmente correta; b) c) e d) são exemplos classificados como parcialmente corretas

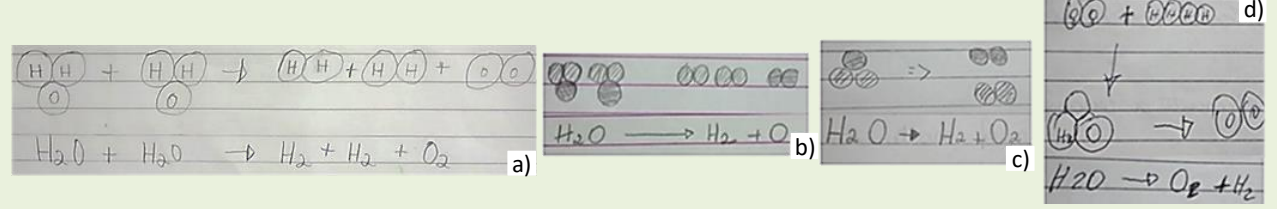

Fonte: do autor

A maioria dos estudantes ( 11 deles, aproximadamente $48 \%$ do total) escreveu as expressões representacionais de forma parcialmente correta (Fig. 10b; 10c; 10d).

Foram consideradas nessa categoria, as seguintes respostas: (1) os modelos foram desenhados adequadamente, mas a equação não corresponde ao que foi representado no modelo, como na Fig. 10b (7 estudantes); (2) os modelos foram desenhados adequadamente, a equação corresponde ao que foi representado no modelo, porém não é considerada a conservação da matéria nas expressões, como na Fig. 10c (3 estudantes); (3) os modelos não foram desenhados adequadamente, mas a equação foi corretamente representada, como na Fig. 10d (1 estudante).

Ao analisar esses resultados nota-se que a maioria dos estudantes conseguiu apresentar expressões representacionais adequadas para descrever, por meio de modelos simbólicos e/ou concretos o fenômeno observado e discutido na aula.

Mesmo com a utilização dos modelos, houve 6 estudantes (aproximadamente 26\%) que construíram os modelos e escreveram a equação incorretamente. Nessas representações, eles ilustratam gases com a representação de apenas um átomo e não como moléculas diatômicas.

Considerando que mais da metade dos estudantes conseguiram representar equações de forma correta ou parcialmente correta, entendemos que as atividades contribuíram para esse aprendizado. 


\section{CONSIDERAÇÕES FINAIS}

Apesar da reconhecida importância dos três níveis do conhecimento químico para o processo ensino-aprendizagem, a literatura ainda carece de pesquisas que investiguem as dificuldades dos estudantes na transição entre eles. Nesse sentido, a partir da presente pesquisa, observou-se que a utilização de sistemas conceituais hierarquicamente organizados e atividades envolvendo modelos podem contribuir para representar os fenômenos nas diferentes formas de representação.

Em nível macroscópico, foram realizadas observações de fenômenos simples que, em seguida, foram discutidos a nível submicroscópico a partir da utilização de sistemas conceituais. Os resultados indicaram que a introdução desses sistemas foi satisfatória para a instução de conceitos científicos, pois os estudantes em suas explicações passaram a apresentar respostas relacionando conceitos de forma adequada, diferentemente de situações anteriores em que palavra era diretamente relacionada ao objeto.

Ao tentar promover essa transição apenas de forma expositiva, o professor não tem acesso à forma como os alunos estão se apropriando das ideias apresentadas. As atividades envolvendo modelos concretos contribuíram para minimizar esse problema, pois os estudantes foram instigados a elaborar modelos mentais e representá-los, permitindo que tivéssemos acesso às suas concepções e dificuldades. Quanto à elaboração da expressão representacional, foi observado que a maioria dos estudantes conseguiu construir uma representação utilizando modelos concretos dos constituintes das substâncias envolvidas na equação e, a partir deles, desenhar modelos adequados para representar a reação observada.

Em relação aos que não conseguiram transcrever a representação concreta, para linguagem química de forma adequada, entendemos que isso pode ser resultante da falta de tempo hábil para a discussão de como são representados os fenômenos por meio da linguagem química, sendo dada maior ênfase na discussão dos modelos concretos. Sugerimos que essa linguagem seja melhor trabalhada, abordando o significado dos símbolos 
presentes em fórmulas e equações para que os alunos entendam essa outra forma de representação.

Nesse sentido, os resultados indicaram que a utilização de sistemas conceituais hierárquicos e o uso de modelos e modelagem, associados à realização de atividades demonstrativo-investigativas, se configuraram como estratégias promissoras para a transição entre os três níveis.

\section{REFERÊNCIAS}

BOGDAN, R. C.; BIKLEN, S. K. Investigação qualitativa em educação: uma introdução à teoria e aos métodos. Porto: Porto Editora LDA, 1994.

FUHR, I. L. Atividades Cotidianas e o pensamento conceitual. Curitiba: CRV, 2018.

GILBERT, J. K. Models and Modelling: Routes to More Authentic Science Education. International Journal of Science and Mathematics Education, v. 2, n. 2, 2004, p. 115-130.

GILBERT, J. K.; TREAGUST, D. F. Introduction: Macro, Submicro and Symbolic Representations and the Relationship Between Them: Key Models in Chemical Education. In: GILBERT, J. K.; TREAGUST, D. (org.). Multiple Representations in Chemical Education. Dordrecht: Springer Netherlands, 2009. p.1-8.

JOHNSTONE, A. H. Macro and Microchemistry. The School Science Review, v. 64, n. 227, 1982, p. 377-379.

JOHNSTONE, A. H. You Can't Get There from Here. Journal of Chemical Education, v. 87, n. 1, 2010, p. 22-29.

JUSTI, R. S. La enseñanza de ciencias basada en la elaboración de modelos. Enseñanza de las ciencias: revista de investigación y experiencias didácticas, v. 24, n. 2, 2006, p. 173-184.

JUSTI, R. S. Modelos e Modelagem no Ensino de Química: Um olhar sobre aspectos essenciais pouco discutidos. In: SANTOS, W. L. P.; MALDANER, O. A. (org.). Ensino de Química em Foco. ljuí: Unijuí, 2011 . p. 209-230.

JUSTI, R. S.; GILBERT, J. K. Modelling, teachers' views on the nature of modelling, and implications for the education of modellers. International Journal of Science Education, v. 24, n. 4, 2002, p. 369-387.

MELO, M. S.; SILVA, R. R. A interação entre conceitos cotidianos e científicos 
no ensino do tema atmosfera. XI Encontro Nacional de Pesquisa em Educação em Ciências (XI ENPEC), Florianópolis-SC, 2017.

MENDONÇA, P. C. C. Influência de atividades de modelagem na qualidade dos argumentos de estudantes de Química do Ensino Médio. 201 1. 272

(Doutorado). Faculdade de Educação, UFMG, Belo Horizonte.

MORTIMER, E. Concepções atomistas dos estudantes. Química Nova na Escola, n. 1, 1995, p. 23-26.

NOVICK, S.; NUSSBAUM, J. Junior high school pupils' understanding of the particulate nature of matter: An interview study. Science Education, v. 62, n. 3,1978, p. 273-281.

ROCHA-FILHO, R. C.; TOLENTINO, M.; SILVA, R. R.; TUNES, E.; SOUSA, E. C. P. D. Ensino de conceitos em Química. III. Sobre de conceitos de substância. Química Nova, v. 11, n. 4, p. 417-419, 1988.

SILVA, R. R.; MACHADO, P. F. L.; TUNES. E. Experimentar sem medo de errar. In: MALDANER, O. A.; MACHADO, P. F. L.; SANTOS, W. L. P. S. Ensino de Química em foco. $2^{a}$ ed. ljuí: Unijuí, 2019, p. 195-215.

SILVA, R. R.; ROCHA-FILHO, R. C.; TUNES, E.; TOLENTINO, M. Ensino de conceitos em Química. II. Matéria: um sistema conceitual quanto à sua forma de apresentação. Ciência e Cultura, v. 38, n. 12, 1986, p. 2028-2030.

TOLENTINO, M.; SILVA, R. R.; ROCHA-FILHO, R. C.; TUNES, E. Ensino de conceitos em Química. I. Matéria: Exemplo de um sistema de conceitos científicos.

Ciência e Cultura, v. 38, n. 10, 1986, P. 1721-1724.

TUNES, E.; TOLENTINO, M.; SILVA, R. R.; SOUSA, E. C. P. D.; ROCHA-FILHO, R. C. Ensino de conceitos em Química. IV. Sobre a estrutura elementar da matéria. Química Nova, v. 12, n. 2, p. 199-202, 1989.

VIGOTSKI, L. Pensamiento y habla. 1. Buenos Aires: Colihue, 2007.

VOGELEZANG, M. J. Development of the concept 'chemical substance' some thoughts and arguments. International Journal of Science Education, $v$. 9 , n. 5, 1987, p. 519-528.

Recebido em: 06 de novembro de 2018 Aprovado em: 08 de maio de 2019 